\title{
$\mathrm{CO}_{2}$ 저감용 혼합재를 시용한 고인성 콘크리트의 개발
}

\section{Development of High-Toughness Concrete Using the Mixed Materials for $\mathrm{CO}_{2}$ Reduction}

$\begin{array}{ccc}\text { 이 성 태 }{ }^{1) *} & \text { 허 형 석 } & \text { 노 재 } \text { 호 }^{3)} \\ \text { Yi, Seong Tae } & \text { Heo, Hyung Seok } & \text { Noh, Jae Ho }\end{array}$

\begin{abstract}
Now-a-days, a manhole adopted since the late 1990s and produced using the polymer concrete has widely used due to the various benefits. While entering the High oil prices times, however, and with the price increase of the petrochemical materials, the cost of manufacture of polymer concrete was elevated and the resulting polymer concrete's weakness is being put on. Accordingly, the development of economic cement concrete manholes, which can replace the outstanding bending strength of manhole made of high-price polymer concrete, has been required. In this study, based on the cement technology of fast hardening armorphous calcium aluminate (ACA), by minimizing the amount of cement using the industrial byproducts, to develop the eco-friendly high-toughness concrete manhole, which can reduce $\mathrm{CO}_{2}$ reduction, was intended. As the results, the cement concrete manhole, which economic, eco-friend, and meeting the performance requirements, was developed.
\end{abstract}

Keywords : High-toughness concrete, $\mathrm{CO}_{2}$ reduction, Mixed materials, Cement concrete manhole, Bending strength

\section{1. 서 론}

우리나라에서 1990년대 중반까지는 주로 일반 시멘트 콘 크리트로 제작된 맨홀을 사용하였고, 1990년대 후반부터 사 용된 폴리머 콘크리트로 제작된 맨홀은 폴리에스테르 수지 결합재의 사용으로 고강도를 실현하여 (Yeon and Joo, 2002), 콘크리트 맨홀의 단면감소, 경량화, 그리고 시공의 용의성 등 뛰어난 장점으로 현재까지 사용되고 있다 $(\mathrm{Kim}$ and $\mathrm{Jo}$, 2007).

폴리머 콘크리트는 결합재로서 시멘트를 사용하지 않고 폴리머와 골재만을 결합한 콘크리트로 높은 가격, 큰 열팽창 계수, 모노머와 수지의 불쾌한 냄새, 고온에 취약하다는 단 점에도 불구하고 압축강도, 인장강도, 휨강도가 일반 시멘트 콘크리트에 비해 매우 우수하며 (Hyung et al., 2005), 조기 에 고강도를 발현하여 통신용 맨홀, 개거 등에 많이 사용되 고 있다.

\footnotetext{
1) 정회원, 인하공업전문대학 토목환경과 교수, 교신저자

2) 정회원, (주)제이엔티아이엔씨 연구팀장

3) 정회원, (주)제이엔티아이엔씨 대표이사
}

그러나, 고유가 시대로 접어들면서 석유화학 재료의 가격 인상과 더불어 폴리머 콘크리트의 제조원가가 상승되고 이 에 따른 폴리머 콘크리트의 약점이 대두되고 있다. 따라서, 고가의 폴리머 콘크리트로 제작된 맨홀의 뛰어난 휨강도를 대체할 수 있는 경제적인 시멘트 콘크리트 맨홀의 개발이 요 구되어 왔다.

일반적인 초고강도 콘크리트의 경우, 높은 압축강도를 발 현하지만 그에 비해 휨강도의 수준은 폴리머 콘크리트에 미 치지 못하고 있다 (Son et al., 2005). 그러나 최근 들어 시멘 트를 이용한 콘크리트 기술의 비약적인 발전으로 가격 경쟁 력은 물론, 고강도와 고인성을 보유한 기능성 콘크리트의 개 발이 가능해졌다 (Kim et al., 2005). 이로 인해 기존 시멘트 계 콘크리트의 단면 증가에 의한 무게 문제가 해소되어 현장 에서의 시공측면에서도 폴리머 콘크리트와 유사한 성능을 나타내고 있다.

Fig. 1은 현재 설치되어 있는 전력구 (power tunnel) 중의

* Corresponding author : yist@inhatc.ac.kr

- 본 논문에 대한 토의를 2013년 6월 30일까지 학회로 보내주시면 2013년 7월호에 토론결과를 게재하겠습니다. 

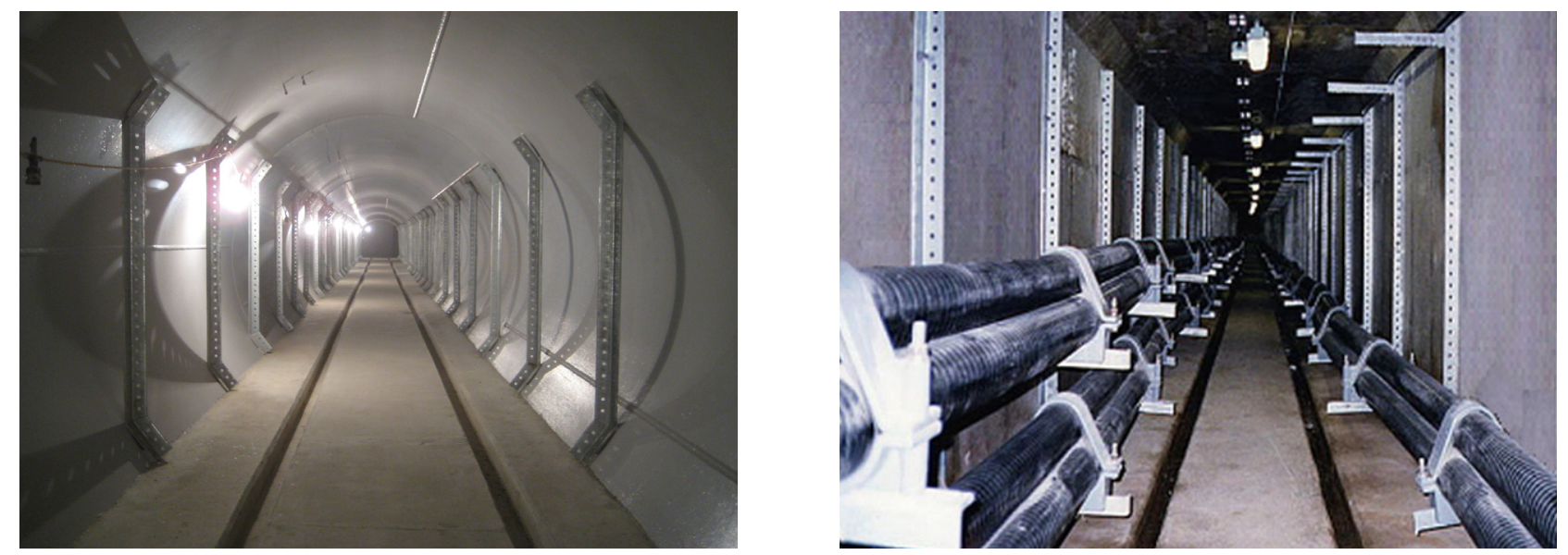

Fig. 1 Examples of the power tunnel

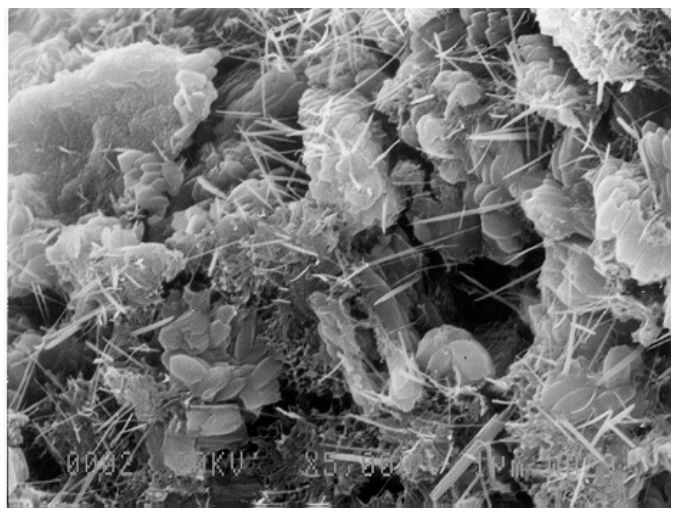

(a) cement hydrate

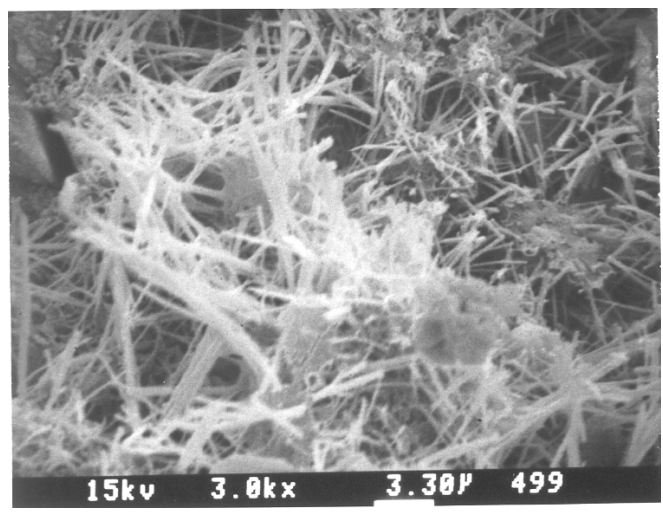

(b) ACA hydrate

Fig. 2 Cement and ACA hydrates

예를 나타낸 것이다. 맨홀은 땅속에 묻은 수도관이나 하수관, 배선 (配線) 따위를 검사하거나 수리 또는 청소하기 위하여 사람이 드나들 수 있게 만든 구멍으로 이들 전력구에 설치되 어 있는 시설 중 일부이다.

시멘트는 혼합수와 반응하여 수화과정에서 시멘트 표면으 로부터 수화물이 생성되어 양생재령이 증가될수록 수화물이 성장하여 고강도를 발현하게 된다 (Kosmatka \& Panarese, 1990). 그러나 수화물의 생성형태와 구조는 인장력의 증가를 촉진시키지 못하는 실정이다.

Fig. 2(a)는 일반적인 시멘트에서의 수화물을 나타내고 고 인성 콘크리트 기술에서는 $\mathrm{ACA}$ 를 이용하여 콘크리트의 혼 합수와 $\mathrm{ACA}$ 의 반응에 의해 Fig. 2(b)와 같이 침상의 결정형 을 갖는 수화물을 생성시켜 시멘트 경화체 조직의 미세구조에 침투하여 콘크리트 인장력을 증대시킨다 (Yoo et al., 2011; Joeng et al., 2002).

본 연구에서는 비정질 칼슘알루미네이트 (Armorphous calcium aluminate, ACA)계의 속경형 시멘트기술을 기반으로 플라이 애쉬와 고로슬래그, 실리카 품, 메타카올린 등의 산업부산물 을 이용하여 시멘트의 사용량을 최소화시킴으로써 $\mathrm{CO}_{2}$ 를 저 감시킬 수 있는 친환경적인 맨홀용 고인성 콘크리트를 개발 하고자 한다.

\section{2. 실험 계획}

\section{1 실험재료}

Fig. 3에서 (a)와 (b)는 각각 폴리머와 시멘트 콘크리트를 사용해서 제작된 맨홀들을 나타내고 있다. 이 연구에서는 맨 홀의 특성상 고인장 콘크리트의 합리적인 배합을 얻기 위해 다음과 같은 재료를 이용하여 실험을 진행하였다.

실험체 제작에 사용된 시멘트로는 KS L 5201에 규정된 보통포틀랜드시멘트 $(\mathrm{OPC})$ 를 사용하였고 잔골재는 하천 모 


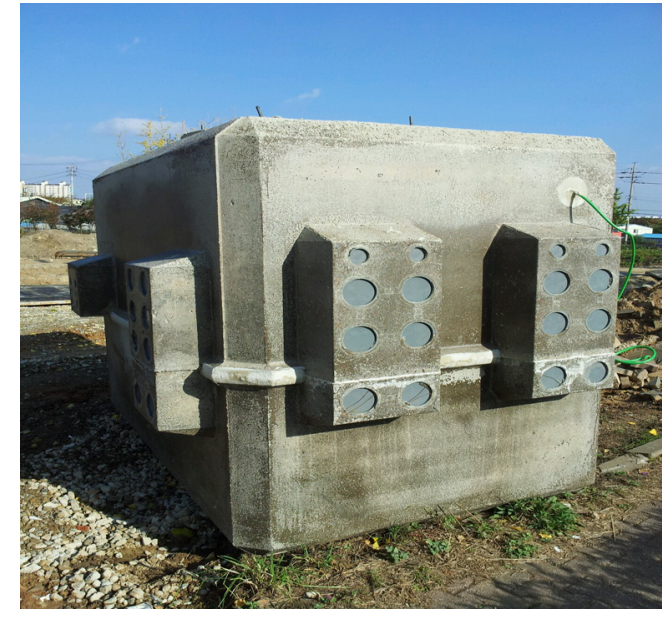

(a) polymer concrete manhole

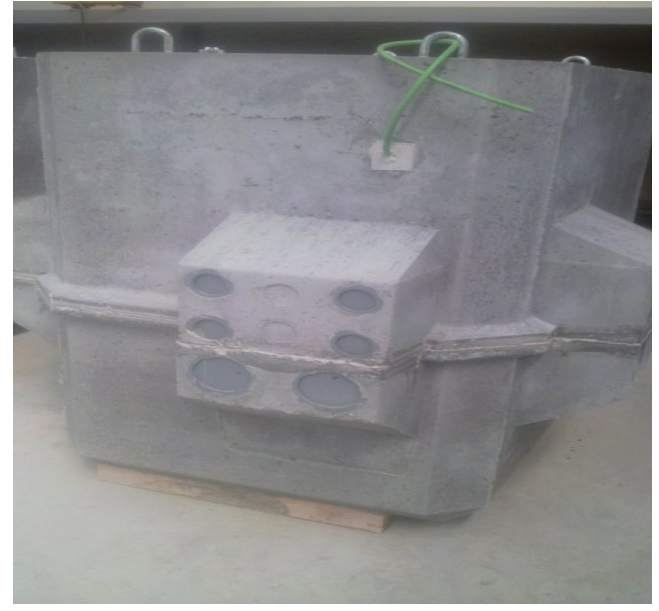

(b) cement concrete manhole

Fig. 3 Polymer and cement concrete manholes

Table 1 Physical properties of the aggregate

\begin{tabular}{c|c|c|c}
\hline Type & Density $\left(\mathrm{g} / \mathrm{cm}^{3}\right)$ & Absorption $(\%)$ & F.M. \\
\hline fine & 2.54 & 1.07 & 2.65 \\
\hline coarse & 2.59 & 0.63 & 5.15 \\
\hline
\end{tabular}

래를 사용하였으며, 굵은 골재는 부순골재를 사용하였다. 굵 은 골재의 최대 치수 $\left(\mathrm{G}_{\max }\right)$ 는 $10 \mathrm{~mm}$ 이며, 실험에 사용된 골 재의 물리적 성질은 Table 1 과 같다.

\section{2 배합}

이 연구에서는 고강도, 고내구성, 경제성, 그리고 작업의 난이도 등 사업화와 관련된 모든 요구조건들을 만족하는 물 성을 찾아내기 위하여 Table 2와 같이 조기강도 발현을 위한 아윈계 (Hauyne) 혼합재, 고강도 혼합재 (high-strength mixed materials, HSMM), filler로 사용되는 각종 산업부산물, 그리 고 조강재의 사용량을 실험변수로 설정하여 배합실험을 실 시하였고, 사용된 분말 혼합재와 filler의 물리적 성질 및 화 학적 성분은 각각 Table 3과 Table 4와 같으며 실험에 사용 된 분말의 배합과 콘크리트 배합은 각각 Table 5 및 Table 6 과 같다.

Table 2 Experimental variables

\begin{tabular}{c|c}
\hline Variable & Usage (\%) \\
\hline Hauyne mixed materials & $5,10,15$ \\
\hline high-strength mixed materials (HSMM) & 13,2328 \\
\hline filler & $5,7,10$ \\
\hline accelerator & 2,4 \\
\hline
\end{tabular}

Table 3 Physical properties and chemical composition of power-type mixed materials

\begin{tabular}{c|c|c|c}
\hline \multirow{2}{*}{$\begin{array}{c}\text { Prop. \& Comp. } \\
\text { physical }\end{array}$} & density & 2.61 & HSMM \\
\cline { 2 - 4 } & blaine $\left(\mathrm{cm}^{2} / \mathrm{g}\right)$ & 5,200 & 2.98 \\
\hline \multirow{4}{*}{$\begin{array}{c}\text { chemical } \\
(\%)\end{array}$} & $\mathrm{SiO}_{2}$ & 7.21 & 5,900 \\
\cline { 2 - 4 } & $\mathrm{Al}_{2} \mathrm{O}_{3}$ & 25.76 & 24 \\
\cline { 2 - 4 } & $\mathrm{Fe}_{2} \mathrm{O}_{3}$ & 1.62 & 0.75 \\
\cline { 2 - 4 } & $\mathrm{CaO}$ & 50.48 & 43.55 \\
\cline { 2 - 4 } & $\mathrm{MgO}$ & 1.33 & 4.5 \\
\cline { 2 - 4 } & $\mathrm{SO}_{3}$ & 6.78 & - \\
\cline { 2 - 4 } & $\mathrm{TiO}_{2}$ & 0.88 & 0.10 \\
\cline { 2 - 4 } & $\mathrm{K}_{2} \mathrm{O}$ & 0.18 & - \\
\cline { 2 - 4 } & $\mathrm{LOI}$ & 5.60 & \\
\hline
\end{tabular}

Table 4 Physical properties and chemical composition of fillers

\begin{tabular}{c|c|c|c}
\hline \multirow{2}{*}{$\begin{array}{c}\text { Prop. \& Comp. } \\
\text { physical }\end{array}$} & density & Silica-fume & Meta-kaolin \\
\cline { 2 - 4 } & blaine $\left(\mathrm{cm}^{2} / \mathrm{g}\right)$ & 190,000 & 2.20 \\
\hline \multirow{4}{*}{$\begin{array}{c}\text { chemical } \\
\text { (\%) }\end{array}$} & $\mathrm{SiO}_{2}$ & 94.0 & 10,000 \\
\cline { 2 - 4 } & $\mathrm{Al}_{2} \mathrm{O}_{3}$ & 0.3 & 52.0 \\
\cline { 2 - 4 } & $\mathrm{Fe}_{2}$ & 0.8 & 40.0 \\
\cline { 2 - 4 } & $\mathrm{CaO}_{3}$ & 0.3 & 3.0 \\
\cline { 2 - 4 } & $\mathrm{MgO}$ & 0.4 & 1.2 \\
\cline { 2 - 4 } & $\mathrm{TiO}_{2}$ & - & 0.5 \\
\cline { 2 - 4 } & $\mathrm{K}_{2} \mathrm{O}+\mathrm{Na}_{2} \mathrm{O}$ & 1.0 & 0.4 \\
\cline { 2 - 4 } & $\mathrm{LOI}$ & 2.8 & 1.0 \\
\hline
\end{tabular}


Table 5 Mixture proportions of the powder

\begin{tabular}{|c|c|c|c|c|c|c|c|c|c|}
\hline Mix type & $\mathrm{OPC}$ & Hauyne mixed materials & HSMM & S.F. & M.K. & $\mathrm{Ca}(\mathrm{OH})_{2}$ & Retarder $^{1)}$ & $\mathrm{SP}^{2)}$ & Defoamer ${ }^{3)}$ \\
\hline No. 1 & 66.7 & 5 & 23 & 5 & - & - & \multirow{12}{*}{0.1} & \multirow{12}{*}{0.7} & \multirow{12}{*}{0.1} \\
\hline No. 2 & 61.7 & 10 & 23 & 5 & - & - & & & \\
\hline No. 3 & 56.7 & 15 & 23 & 5 & - & - & & & \\
\hline No. 4 & 59.7 & 10 & 23 & 7 & - & - & & & \\
\hline No. 5 & 56.7 & 10 & 23 & 10 & - & - & & & \\
\hline No. 6 & 61.7 & 10 & 23 & - & 5 & - & & & \\
\hline No. 7 & 59.7 & 10 & 23 & - & 7 & - & & & \\
\hline No. 8 & 56.7 & 10 & 23 & - & 10 & - & & & \\
\hline No. 9 & 71.7 & 10 & 13 & 5 & - & - & & & \\
\hline No. 10 & 56.7 & 10 & 28 & 5 & - & - & & & \\
\hline No. 11 & 59.7 & 10 & 23 & 5 & - & 2 & & & \\
\hline No. 12 & 57.7 & 10 & 23 & 5 & - & 4 & & & \\
\hline
\end{tabular}

${ }^{1)}$ acid powder typed detarder, ${ }^{2)}$ powder typed polycarboxylic superplasticizer, ${ }^{3)}$ silicon typed powder defoamer

Table 6 Mixture proportion of the concrete

\begin{tabular}{c|c|c|c|c|c|c}
\hline \multirow{2}{*}{$\begin{array}{c}\text { W/B } \\
(\%)\end{array}$} & \multirow{2}{*}{$\begin{array}{l}\mathrm{S} / \mathrm{a} \\
(\%)\end{array}$} & \multicolumn{5}{|c}{ Unit mass $\left(\mathrm{kg} / \mathrm{m}^{3}\right)$} \\
\cline { 3 - 7 } & $\mathrm{W}$ & $\mathrm{B}$ & $\mathrm{S}$ & $\mathrm{G}$ & $\mathrm{SP}^{1)}$ \\
\hline 21 & 44 & 115 & 546 & 600 & 740 & $\mathrm{~B} * 4 \%$ \\
\hline
\end{tabular}

${ }^{1)}$ liquid typed polycarboxylic superplasticizer

\section{3 성능평가기준}

지하에 매설되는 맨홀은 (1) 자체의 특성상 고강도, (2) 전 력구로 인해 인장력이 가해지는 외력의 특성에 저항하기 위 한 고인장강도, 그리고 (3) 제품생산에 따른 작업성과 성형성 을 확보하기 위해 일정 수준의 슬럼프 값이 요구되며, 그에 따른 요구성능은 Table 7에 나타내었다. 여기서 슬럼프 실험 은 Fig. 4에 나타낸 미니슬럼프콘을 사용하여 수행했다. 미 니슬럼프콘에 콘크리트를 2 층으로 채워넣고 각층은 25 회 다 진 후 슬럼프콘을 들어올려 콘크리트가 가라앉은 높이를 측 정하였다.

\section{3. 실험결과 및 분석}

현장에 적용 가능한 제품을 만들기 위해서는 소요강도와 작업성을 모두 만족해야하므로 제품개발을 위한 결과분석은 함께 이루어져야한다.

고인장 콘크리트는 압축강도와 휨강도를 측정하였고, 압축 강도는 KS L 5105에 따라 시험체를 제작하고, 휨강도 시험 체는 KS F 2476에 의거하여 40×40×160 (mm) 각주형 공시 체로 제작하였다. 모든 시험체는 2 시간 (탈형강도용), 1,3 그리고 28 일 재령별로 3 개씩 제작하였으며, 제작 후 한시간
Table 7 Performance evaluation criteria

\begin{tabular}{c|c|c|c}
\hline Item & Standard & Value & Reference \\
\hline \multirow{2}{*}{$\begin{array}{c}\text { compressive } \\
\text { strength }\end{array}$} & \multirow{2}{*}{ KS F 2560 } & $80 \mathrm{MPa}$ & 1day \\
\cline { 3 - 4 } $\begin{array}{c}\text { bending } \\
\text { strength }\end{array}$ & & $20 \mathrm{MPa}$ & 1day \\
\hline slump & - & $120-140 \mathrm{~mm}$ & mini slump cone \\
\hline
\end{tabular}
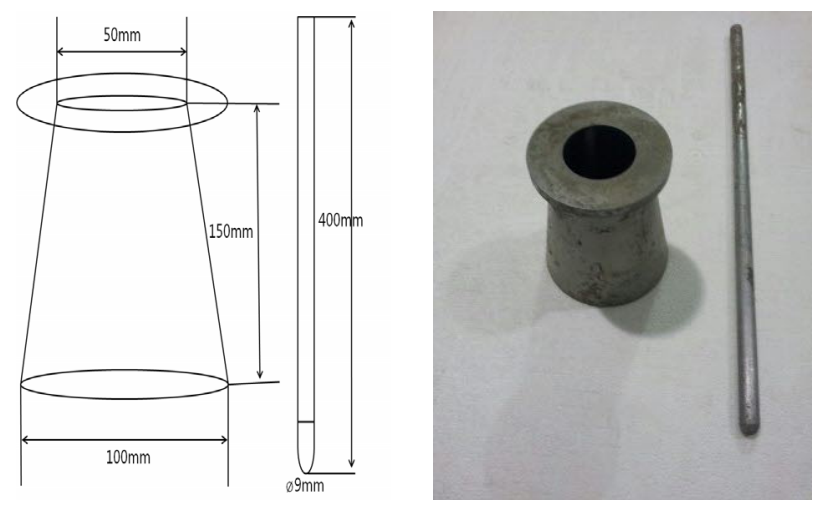

Fig. 4 Mini slump cone

동안 전치 (1차양생), 3 시간 동안 $40^{\circ} \mathrm{C}$ 에서 증기양생 후 탈 형, 20 시간 동안 $70^{\circ} \mathrm{C}$ 에서 증기양생 (2차양생)을 실시한 후, 1 일 동안 상온에서 습포양생 ( 3 차양생)을 거처 양생한 후 각 재령에 맞추어 수중양생을 실시한 후 측정하였다.

현장의 작업성 평가와 맨홀의 성형성을 판단하기위하여 KS F $2402(\varnothing 100 \times 200 \mathrm{~mm}$ 의 원주공시체 $)$ 에 의해 실험하였 으며, 초기와 30 분 후의 슬럼프를 측정하여, 작업유지성능을 확인하였다. 


\section{1 압축강도와 슬럼프}

실내실험을 통하여 얻은 압축강도의 실험결과는 Fig. 5 와 같고 작업성과 맨홀의 성형성 판단을 위한 슬럼프 측정값은 Fig. 6에 나타내었다. 그리고 Fig. 7에서는 각 배합별 슬럼프 손실량을 검토하였다. 이 그림에서 세로축은 initial값-30min 후의 값을 나타낸다.

Fig. 5, Fig. 6 그리고 Fig. 7 의 No. 1, No. 2, No. 3 배합 을 살펴보면, 아윈계 조강재의 사용량의 증가에 따라 초기의 강도발현률도 증가하지만, 재령이 지남에 따른 강도발현 양 상은 No. 2의 경우가 가장 높은 값들을 보여줌을 알 수 있었다. 작업성 판단을 위한 슬럼프값 측정의 경우, 아윈계 조강재 의 사용량이 증가함에 따라 초기슬럼프는 적어지고, loss 또 한 큰 것으로 나타났다. No. 3 배합의 경우, 초기 높은 강도

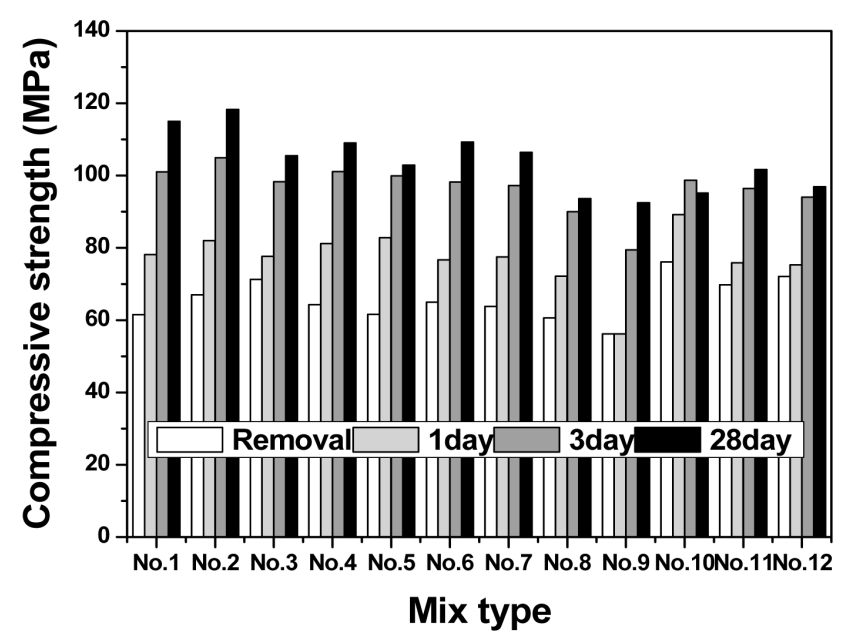

Fig. 5 Compressive strengths with mix type

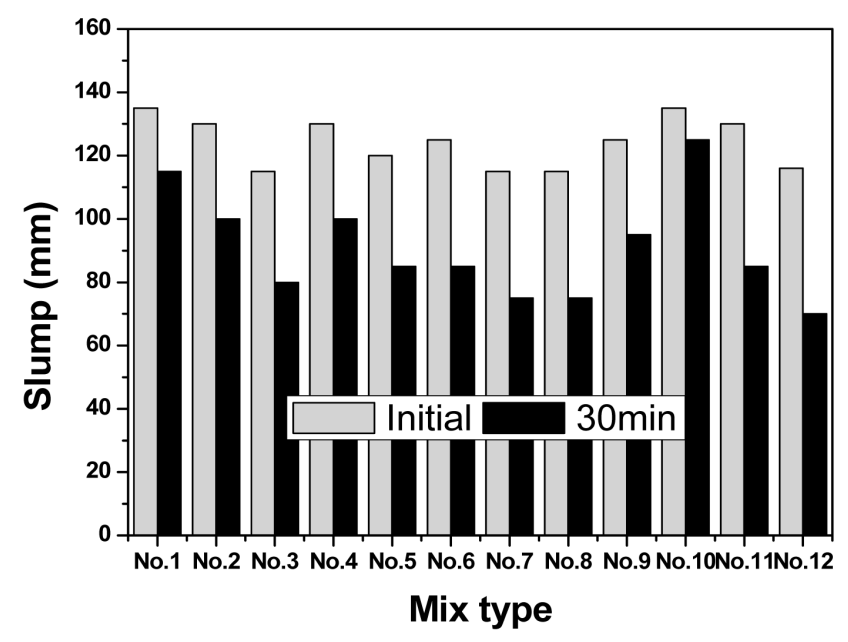

Fig. 6 Slump values with mix type

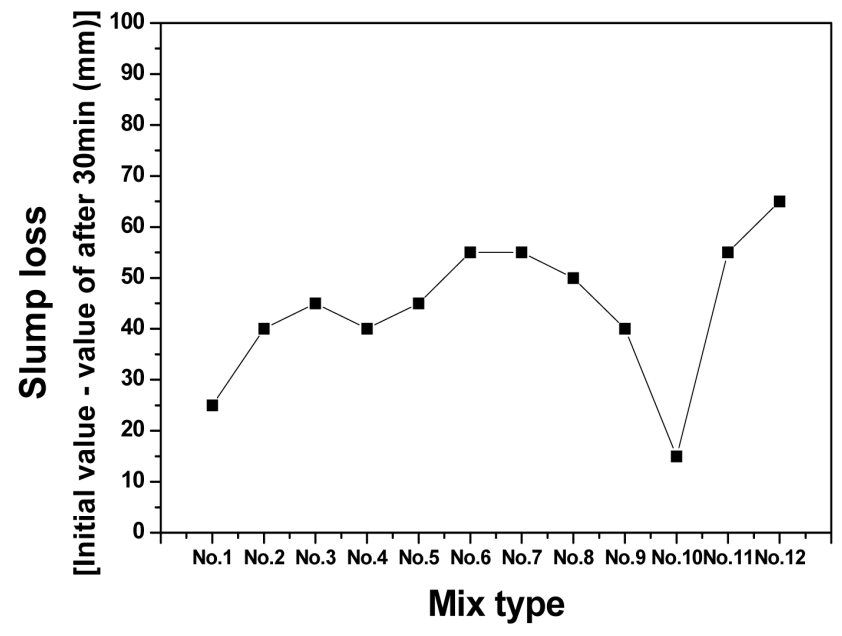

Fig. 7 Slump loss values with mix type

값을 나타내지만 장기재령으로 갈수록 강도발현률이 현저히 줄어들어 $15 \%$ 사용량은 과다한 것으로 판단된다.

또한, No. 1 배합의 경우, 재령이 지날수록 높은 강도발현 률을 나타내고 작업성에서도 우수한 경향을 나타내었으나, 모든 재령의 강도에서 No. 2 배합에 비해 떨어지는 값을 나 타내며 따라서 아윈계 혼합재의 비율은 $10 \%$ 가 적당할 것으 로 판단되었다.

Filler의 종류와 사용량에 따른 강도와 작업성 판단을 위해 실리카 품 $5,7,10 \%$ 를 사용한 No. 2, No. 4, No. 5 배합과 메타카올린 5, 7, 10\%를 사용한 No. 6, No. 7, No. 8 배합 을 살펴보면, 실리카 품과 메타카올린의 사용량이 증가할수 록 초기와 장기 모두에서 강도가 저하되는 경향을 나타냈다. 초기와 장기강도, 작업성의 측면에서도 사용량이 같을 경우, 모두 실리카 품을 사용한 경우가 우수한 물성을 나타내었고, 적정한 사용량은 $5 \%$ 인 것으로 나타났다.

고강도 혼합재의 사용량 (No. 2, No. 9, No. 10)에 따른 강도 및 작업성을 살펴보면, 고강도 혼합재의 사용량이 가장 높은 No. 10 배합의 경우 다른 배합에 비해 높은 슬럼프및 슬럼프유지력을 나타내고, 재령 1 일과 3 일에서 가장 높은 초 기 압축강도를 발현하였으나, 재령 28일에서는 오히려 압축 강도가 저하되는 것으로 나타났다. 이는 고강도 혼합재를 다 량 사용하여 초기 강도발현률은 높으나 장기강도에는 악영 향을 미친 것으로 사료되며, 따라서 고강도 혼합재의 경우에 도 적정 사용량은 $23 \%$ 로 판단된다.

추가로 사용된 기타 조강재 $\left(\mathrm{Ca}(\mathrm{OH})_{2}\right)$ 의 영향 $(\mathrm{No} .2$, No. 11 , No. 12)을 살펴보면, No. 2 배합과 비교하여 조강재의 함량이 올라감에 따라 초기 탈형강도와 1 일 압축강도는 올 
라가지만, 재령 3 일과 28 일에서 압축강도가 오히려 저하되는 현상을 보이며, 작업성 (Fig. 7) 면에서는 굳지 않은 콘크리 트의 30 분 후 슬럼프의 손실량이 가장 큰 것으로 나타남으로 써, $\mathrm{Ca}(\mathrm{OH})_{2}$ 계 조강재의 사용은 콘크리트의 장기강도 및 작 업성 확보에 악영향을 미치는 것으로 판단된다. Fig. 7 에서 각 data값은 슬럼프 손실량을 나타내고 있으며, 특히 No. 12 는 30 분 경시후 가장 큰 슬럼프 손실 $(60 \mathrm{~mm})$ 이 발생된 것 을 알 수 있고, No. 10 은 가장 적은 슬럼프 손실량 $(15 \mathrm{~mm})$ 을 나타내었다. 또한 조강재 사용량이 높을수록 손실량은 커 지고 (No. 11, No. 12) 고강도 혼합재는 사용량이 높을수록 손실량은 작아진 것을 알 수 있다 (No. 9, No. 10). 아윈계 조강재 또한 사용량이 증가 (No. 1, No. 2, No. 3)될수록 슬 럼프 손실량이 커지는 것을 알 수 있다.

\section{2 휨강도}

지하에 매설되는 맨홀의 특성상, 압축강도는 물론 전력구 의 장력에 의해 외력으로 작용하는 인장력에 저항하는 휨강 도의 특성 또한 매우 중요하다. 이에 휨강도의 측정결과를 Fig. 8에 나타내었다.

Fig. 8 의 휨강도 측정결과를 살펴보면 No. $2,3,6$, 그리고 10 의 배합에서 1 일 휨강도 기준인 $20 \mathrm{MPa}$ 를 상회하는 것으 로 나타났다.

최종적으로, 콘크리트의 기본 물성인 압축강도와 슬럼프 그리고 휨강도에 대한 요건 모두를 만족하는 최적 배합을 No. 2 배합으로 선정하였으며, 이를 현장생산에 적용하여 현 장에의 적용성에 대한 평가를 실시하였다.

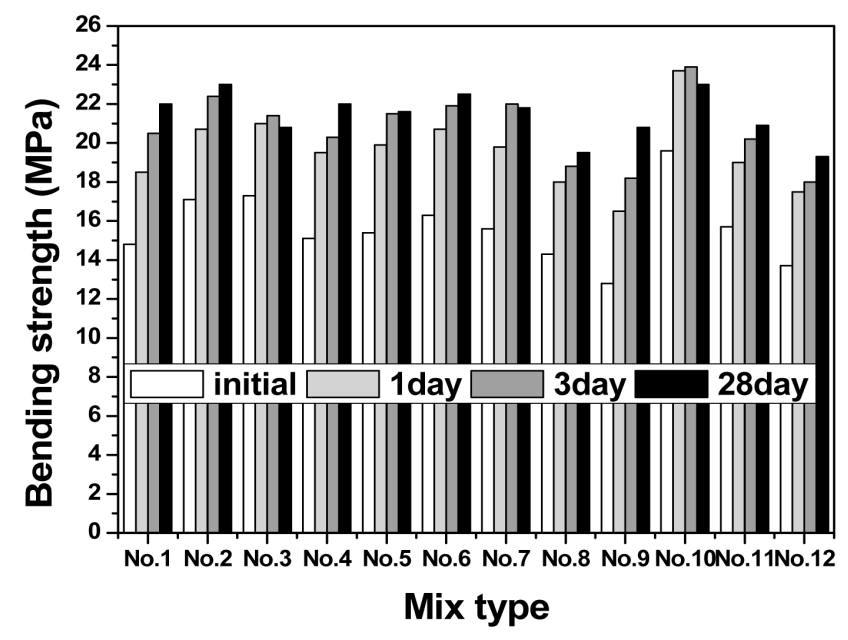

Fig. 8 Bending strengths with mix type

\section{4. 현장에의 적용성 평가}

현장에서의 적용성 평가를 위해 국내에 소재하고 있는 D 사의 현장에 사용되는 배합과 공정에 이 연구의 결과 (No. 2 배합)를 적용하였으며, 현장에서 사용되고 있는 평가방법에 맞추어 탈형강도와 1 일 압축강도를 측정하였다. 압축강도 측 정을 위한 시편은 멘홀성형과 동시에 $\varnothing 100 \times 200(\mathrm{~mm})$ 의 원주공시체를 이용하여 제작하였으며, 제작 후 한시간 동안 전치 (1차양생), 3 시간 동안 $40^{\circ} \mathrm{C}$ 에서 증기양생 후 탈형, 20 시간 동안 $70^{\circ} \mathrm{C}$ 에서 증기양생 ( 2 차양생)을 실시한 후, 1 일동 안 상온에서 습포양생 ( 3 차양생)을 거처 양생한 후 각 재령 에 맞추어 수중양생을 실시한 후 측정하였다.

현장 배치플랜트를 이용한 멘홀성형 결과는 Fig. 9에 나타 낸 바와 같이 미려한 외관을 나타냄을 알 수 있었다. 한편 Fig. 10과 Fig. 11은 현장에서 얻은 강도의 측정결과를 나타 내고 있다. 실내시험에서 가장 우서한 성능을 나타낸 No. 2 배합을 사용하여 현장조건에서 시험생산한 결과, 초기 거푸 집 탈형후 측정 압축강도가 $69 \mathrm{MPa}, 1$ 일에 $105 \mathrm{MPa}$ 의 압 축강도를 발현하여 평가기준 이상을 나타내었으며, 휨강도는

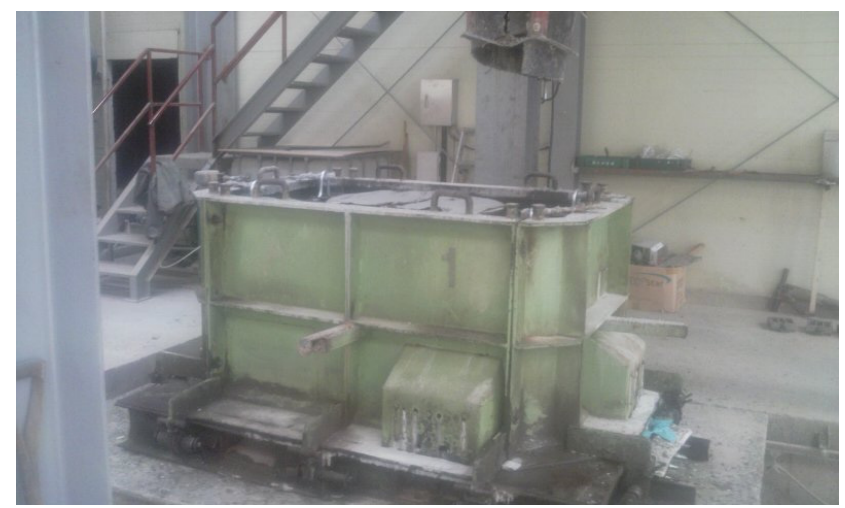

(a) batch plant of the site

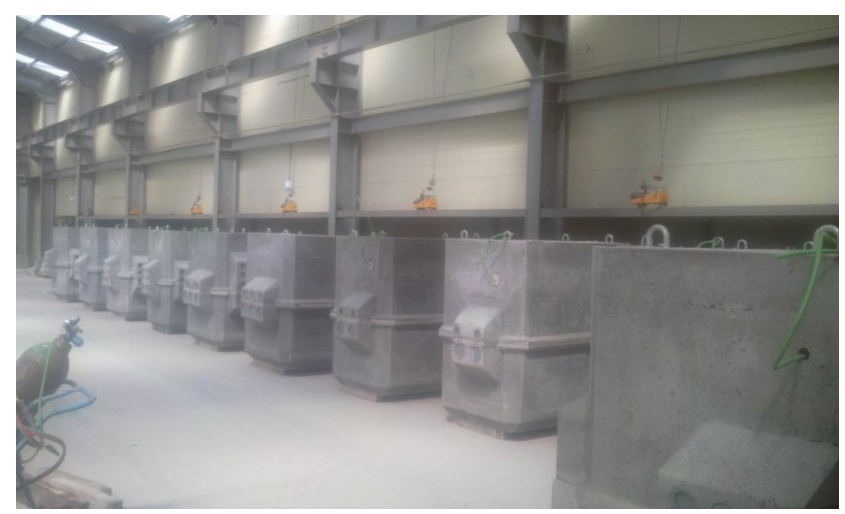

(b) specimens after removing of the form

Fig. 9 Specimens used in evaluation of site applicability 


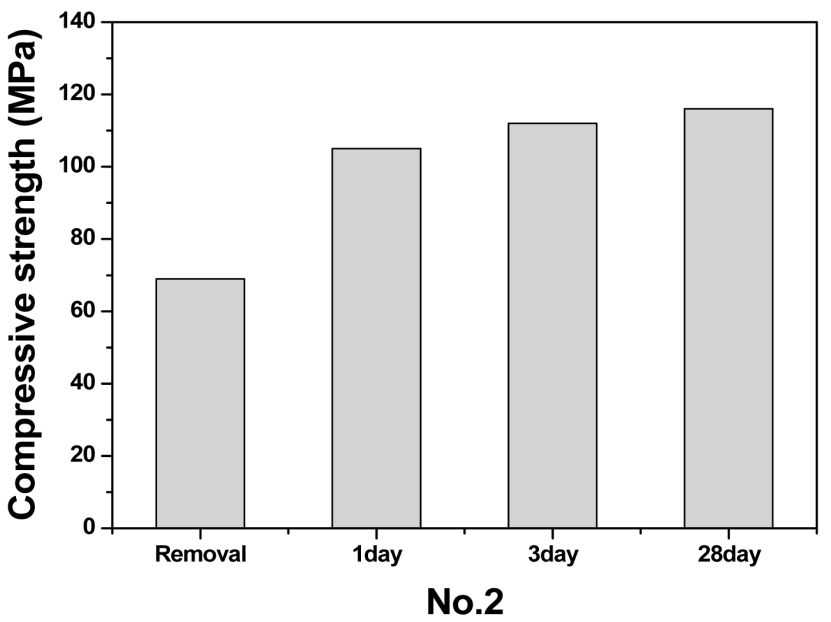

Fig. 10 Compressive strengths with age of mix type No. 2 (site measurement)

1일에 $21 \mathrm{MPa}$ 로 모두 규격을 만족하였다. 따라서, 공정시험 생산에서도 예비 실내실험이상의 강도 결과를 나타내며 다 소 우수한 강도가 발현됨을 확인하였다.

\section{5. 결 론}

$\mathrm{CO}_{2}$ 저감용 혼합재를 사용한 고인성 콘크리트의 개발에 대한 본 연구에서는 시멘트 콘크리트를 이용하여 기존에 사 용되는 폴리머 콘크리트와 동등이상의 수준인 1일 압축강도 $80 \mathrm{MPa}$ 와 휨강도 $20 \mathrm{MPa}$ 이상의 물성을 얻기 위해 수행하 였다. 실내실험과 현장에의 적용시험을 거쳐 물성과 작업성 을 평가했으며, 그 결과를 정리하면 다음과 같다.

(1) 아윈계 조강재의 사용량이 증가함에 따라 초기 탈형강 도는 증가한다. 그러나 장기강도와 슬럼프에는 불리한 것으로 나타났다. 아윈계 혼합재의 비율은 $10 \%$ 가 적 당할 것으로 판단되었다.

(2) 실리카 흠과 메타카올린의 사용량이 증가할수록 모든 배합에서 강도는 저하되는 것으로 나타났다. 실험에 사용된 고강도 배합을 위한 filler의 경우 실라키 흠 5\% 가 가장 유리한 것으로 나타났다.

(3) 고강도 혼합재의 사용량이 높을 경우, 작업성과 유지 력또한 뛰어난 것으로 나타났고, 양생재령 1 일과 3 일 에서 높은 강도발현률을 나타냈으나, 28일에서 오히려 강도가 저하되는 현상이 나타났다.

(4) 기타 조강재의 혼입결과, 조강재 혼입에 따라 작업성 은 현저히 저하되며, 초기 탈형강도를 제외하고 모든

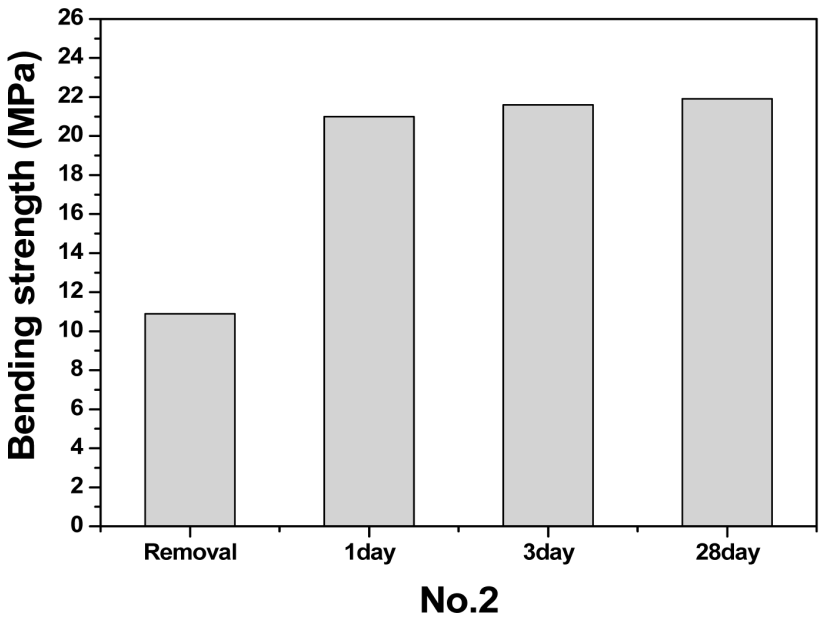

Fig. 11 Bending strengths with age of mix type No. 2 (site measurement)

재령에서 강도저하의 현상을 나타내었다.

(5) 실내실험을 통해 선정된 배합 (No. 2 배합)을 실제 현 장조건에 적용하여 실험한 결과, 실내실험에서 선정된 배합과 비교하여 실내실험의 결과보다 우수한 $105 \mathrm{MPa}$ 이상의 압축강도와 $21 \mathrm{MPa}$ 이상의 휨강도를 나타내 었다.

\section{감사의 글}

이 논문은 2012학년도 인하공업전문대학 교내연구비지원 에 의하여 연구되었음.

\section{References}

1. Hyung, W. G., Kim, W. K., Soh, Y. S., "Durability of Polymer-Modified Mortars Using Acrylic Latexes with methyl Methacrylate", Journal of the Korea Concrete Institute, vol. 17, No. 3, 2005, pp.411-418. (in Korean)

2. Joeng, S. C., Song, M. S., Lee, K. H., Han, C. G., "Hydration of Expansive materials with CSA-System", Journal of the Korea Concrete Institute, vol. 14, No. 5, 2002, pp.631-637. (in Korean)

3. Kim, M. H., Kim, H. H., Kim, Y. R., Kim, Y. D., “An Experimental Study on the Mechanical Properties of HPFRCCs Reinforced with the Micro and Macro Fibers", Journal of the Korea Concrete Institute, vol. 17, No. 2, 2005, pp.263-271. (in Korean)

4. Kim, W. K., Jo, Y. K., "Strength Properties of PolymerModified Repair Mortars According to Curing Conditions and Repair Methods", Journal of the Korea Concrete Institute, vol. 19, No. 6, 2007, pp.457-465. (in Korean)

5. Kosmatka, S. H., Panarese, W. C., "Design and Control of 
Concrete Mixtures", Portland Cement Association (PCA) Thirteenth Edition, 1990, pp.12-15.

6. Son, Y. J., Choi, M. K., Kim, K. K., Park, H. G., Yang, D. I., Jung, S. J., "An Experimental Study on the Factors of Strength of Ultra High-Strength Concrete", Journal of the Korea Concrete Institute, vol. 17, No. 1, 2005, pp.41-44. (in Korean)

7. Yeon, K. S., Joo, M. K., "Status and Future Prospect of Precast Products Using Polymer Concrete", Journal of the Korea Concrete Institute, vol. 14, No. 6, 2002, pp.49-54. (in Korean)

8. Yoo, D. Y., Park, J. J., Kim, S. W., Yoon, Y. S.,
"Evaluating Early Age Shrinkage Behavior of Ultra High Performance Cementitious Composites (UHPCC) with CSA Expansive Admixture and Shrinkage Reducing Agent", Journal of the Korea Concrete Institute, vol. 23, No. 4, 2011, pp.441-448. (in Korean)

1990년대 후반부터 사용된 폴리머 콘크리트로 제작된 맨홀은 이 맨홀이 가지고 있는 다양한 장점 때문에 현재까지 널리 이용되고 있다. 그러나, 고유가 시대로 접어들면서 석유화학 재료의 가격인상과 더불어 폴리머 콘크리트의 제조원가가 상승되고 이에 따른 폴리머 콘크리 트의 약점이 대두되고 있다. 따라서, 고가의 폴리머 콘크리트로 제작된 맨홀의 뛰어난 휨강도를 대체할 수 있는 경제적인 시멘트 콘크리트 맨홀의 개발이 요구되어 왔다. 본 연구에서는 비정질 칼슘알루미네이트 (Armorphous calcium aluminate, ACA)계의 속경형 시멘트기술을 기반으로 플라이 애쉬와 고로슬래그, 실리카 품, 메타카올린 등의 산업부산물을 이용하여 시멘트의 사용량을 최소화시킴으로써 $\mathrm{CO}_{2}$ 를 저 감시킬 수 있는 친환경적인 맨홀용 고인성 콘크리트를 개발하고자 하였다. 연구결과, 경제적이고 친환경적이면서도 요구성능을 만족시키는 시멘트 콘크리트 맨홀을 개발하였다.

핵심 용어 : 고인성 콘크리트, $\mathrm{CO}_{2}$ 저감, 혼합재, 시멘트 콘크리트 맨홀, 휨강도 